\title{
Italian general election 2018: digital campaign strategies. Three case studies: Movimento 5 Stelle, PD and Lega
}

\author{
Calò, Ernesto Dario; Faggiano, Maria Paola; Gallo, Raffaella; Mongiardo, Melissa \\ Department of Communication and Social Research (CoRiS), Sapienza University, Rome, \\ Italy.
}

\begin{abstract}
The advent of the Network Society has brought substantial transformations also in the politics, which, like other areas of society, is affected by important changes. The network, which regulates social relations, has become the place of political discussion and that is where the most substantial part of the electoral campaign for the 2018 general election took place. The object of our research is the observation of the political propaganda of the Movimento 5 Stelle, the Partito Democratico and the Lega (the three most voted parties in the Italian elections) through the institutional accounts of the political parties on Facebook. Once collected a research sample of 1,397 posts officially published online on the three monitored accounts, the aim of our analysis is to investigate the communication strategies of the parties in a phase of hybrid democracy crossed by a deep crisis of political representation. From our analysis it emerges how the three political forces, that refer to different electorates, organize their electoral propaganda, each according to their own strategy.
\end{abstract}

Keywords: Political election 2018; Networked politics; Digital campaign; Movimento 5 Stelle; Partito Democratico. 


\section{Introduction}

On the eve of the vote for the 2018 general election, Italy, like the other mature Western democracies, is undergoing a deep crisis of political representation (Manin, 2016). This crisis is linked to several factors, including: the end of ideologies that has progressively transformed the traditional forms of political participation (Fukuyama, 1992); the digitalization of the social sphere that led to the birth of the Network Society (Castells, 2009) and of the networked individualism (Raine, Wellman, 2012); the distrust of political parties and institutions that operate in a political arena regulated by marketing and communication and which sees in social networks the real places of political participation and discussion.

It is a new society characterized by a hybrid environment. It results problematic for traditional political forces that are dealing with a metamorphosis of representative democracy, of its languages and its communication (Chadwick, 2013).

In addition to this, even from a strictly political point of view, the scenario appears to be complex: the affirmation of the Movimento 5 Stelle, as a post-ideological party, has contributed to erode the consensus of the traditional parties and has broken the traditional bipolarity regulated by the right/left alternation. The splitting of the Partito Democratico has led to a fragmentation of the left-wing area, unable to build a unitary political proposal. Abstentionism and non-voting represent a consistent block of voters who in a consolidated democracy are to be considered as a real political force that claims its right to not choose (Manin, 2016). Italy, in line with international and European political trends, is object of a return to nationalist sentiments (Holtz-Bacha, 2016) and, in the European context, represents one of the most interesting case studies of populism. Populism, as a consequence of the conflict between people and the elite (Diamanti, Lazar, 2018). Logically, all this events affect on the tones and the languages of political parties, in a phase definited "of permanent postmodern electoral campaign", characterized by the use of the network and by a fluid electorate that must be struck by the tones of a captivating communication (Norris, 2000).

According to the $\mathrm{Law}^{1}$, the 2018 election campaign is the first in which political parties receive no public funding from the State; therefore, it is an electoral campaign that needs "zero cost" instruments and that sees in the social networks the most democratic communication tool equally available to all political parties.

\footnotetext{
${ }^{1}$ Decree Law December 28, 2013 n. 149.
} 
The electoral result has given back to Italy an apparent condition of ungovernability: a tripolar scenario characterized by very different political forces and by their irreconcilable nature.

Starting from this assumption, our attention is focused on the analysis of the online campaign of the Movimento 5 Stelle, the Lega and the Partito Democratico, observed and analyzed through the institutional profile of the political parties on Facebook, with the aim of identifying a clear map of the communication strategies of each political parties and of observing the flow of communication addressed to the voters without the mediation of third parties.

This research interest originates from the hypothesis that the new mediated political scene, as an object of substantial distortions, regulated by an immediate communication, represents the privileged seat of negative communication strategies and attacks of the opponents, who aim to obtain the consensus by pointing at the elaboration of strongly emotional and not very rational messagges.

\section{Research methodology}

The object of our analysis is the online electoral campaign officially managed by those political parties that have obtained the highest number of votes: the Movimento 5 Stelle, the Lega and the Partito Democratico. We have chosen to focus our attention on Facebook, because it is the most widespread social network and it is the one that allows a more direct interaction between politicians and users and also because it is a real social marketing tool, as an indispensable tool to communicate the politics and its propaganda. Our monitoring consisted in the collection of all posts and contents published by the political parties. It took place during two stages: the first and last weeks of the electoral campaign (from 5 to 11 February and from 26 February to 4 March). This preparatory part of our research returned a total corpus of analysis of 1,397 posts collected, as said, from the official Facebook pages of the main three political parties.

After having a review of the existing literature on the subject, we have constructed a data matrix to analyze each of the posts in a detailed manner, according to a series of variables considered relevant for the analysis of the communication strategy of the three political parties.

Every data collected were treated from a quantitative point of view to describe the frequency and the intensity of the post publication activities of each considered party and then from a qualitative point of view, in order to investigate the kinds of diffused material, their contents and their related function, witg the im of returning a clear trend of the communication strategies of each political force. 


\section{The corpus of analysis and the intensity of the publication activities}

The sample analyzed consists of 1,397 posts published by the Lega, the Movimento 5 Stelle (M5S) and the Partito Democratico (PD): 680 posts during February 5-11 and 717 posts during February 26-March 4).

It is evident (Table 1.) that in the two weeks considered the volume of published posts is almost stable and describes the same intensity of the publication activities. The substantially stable percentages (with a slight increase in activities during the second week) describe that the political parties reseverd the same attention at the opening and closing of the electoral campaign: $48.68 \%$ vs. $51.32 \%$.

Table 1. Number of posts published by political party per week

\begin{tabular}{lcc}
\hline Week & $\boldsymbol{\%}$ & In absolute terms \\
\hline February 5-Febaury 11 & 48.68 & 680 \\
February 26-March 4 & 51.32 & 717 \\
\hline Total & $\mathbf{1 0 0}$ & $\mathbf{1 , 3 9 7}$ \\
\hline
\end{tabular}

Source: Our elaboration.

In the two weeks considered, the trend of posts publication remains substantially stable, without significant variations. It cannot be said the same about the communicative intensity of the three political parties. In looking at the posts publication activity of the Movimento 5 Stelle, the Lega and the Partito Democratico (Table 2.), it is evident that the Lega represents $73.16 \%$ of the total volume of posts of the general sample. The Lega published average of about 500 posts a week and about 70 posts a day, marking a substantial difference comparing to the other two political parties. The Lega is distinguished by a posts publication activity "almost obsessive", that aims a constant contact with voters throughout the day; it is not the same for the Movimento 5 Stelle and for the Partito Democratico, that have had much lower percentages. In particular, the Partito Democratico represents $7.02 \%$ of the entire sample, that corresponds to a poor use of the network as a propaganda tool, slightly oscillating between the first and second week of detection. The Movimento 5 Stelle, with a decidedly more contained trend compared to that of the Lega, increases the production of electoral propaganda online during the second week, making the most of at the closing phase of the electoral campaign. 
Calò, E. D.; Faggiano, M. P.; Gallo, R.; Mongiardo, M.

Table 2. Number of posts per week ( $\%$ of the total number of posts)

\begin{tabular}{lccc}
\hline Political Party & February 5-11 & February 26-March 4 & Total \\
\hline Lega & $37.44 \%$ & $35.72 \%$ & $73.16 \%$ \\
M5S & $8.23 \%$ & $11.60 \%$ & $19.83 \%$ \\
PD & $3.01 \%$ & $4.01 \%$ & $7.02 \%$ \\
\hline Total & $48.68 \%$ & $51.32 \%$ & $\mathbf{1 0 0 \%}$ \\
\hline \multicolumn{4}{c}{ Source: Our elaboration. }
\end{tabular}

\section{Type of posts}

To be able to investigate the communication of each party, we have developed an easy tool of analysis aimed at identifying the descriptive categories of the different types of post, in order to better describe the communicative style of each party. We have built a variables based analysis according to the following descriptive methods: Link (posts containing a link that refers to an external page), Photo (photographs and images of electoral propaganda), Video (direct events, electoral spots, excerpts of transmissions television), Status (post of written text only). The most used post type of the total sample of analysis (Table 3.) is the image (45.45\%), because, as happens in the offline electoral campaign, is exploited for the immediacy of its communication that can directly catch the attention of the voter. The use of the images, between the first and second week of relevation, is clearly increasing, posts of external links to the social platform are drastically reduced, while a post of only text requires a greater activation effort from the user.

Table 3. Posts publication style

\begin{tabular}{lccc}
\hline Type of posts & February 5-11 & February 26-March 4 & Total \\
\hline Photo & $41.32 \%$ & $49.37 \%$ & $45.45 \%$ \\
Link & $40.15 \%$ & $23.85 \%$ & $31.78 \%$ \\
Video & $18.24 \%$ & $25.80 \%$ & $22.12 \%$ \\
Status & $0.29 \%$ & $0.98 \%$ & $0.64 \%$ \\
\hline Total & $\mathbf{1 0 0 . 0 0 \%}$ & $\mathbf{1 0 0 . 0 0 \%}$ & $\mathbf{1 0 0 . 0 0 \%}$ \\
\hline \multicolumn{4}{c}{ Source: Our elaboration. }
\end{tabular}

The three political parties managed the online electoral campaign according to different communication styles (Table 4.). The Movimento 5 Stelle, unlike the Lega and the Partito Democratico (that prefer the use of images), prefers in its communication the use of video ( $49.93 \%$ posts) to the detriment of the image $(25.27 \%)$. If the verbal communication 
(Status) requires a greater interaction from the user, the Lega - which, as we have seen, is the most active political party on the network - does not use this type of post at all, preferring the immediacy of the images, that correspond to over $50 \%$ of its sample. Posts of Status, which represent the smallest part of the total sample, with only 9 total posts, have been mainly made by the Partito Democratico, which, in considering a lack of capabilities of the use of the network, uses less immediate and captivating languages.

Table 4. Posts publication styles adopted by political parties

\begin{tabular}{lccc}
\hline Types of post & Lega & M5S & PD \\
\hline Photo & $50.78 \%$ & $25.27 \%$ & $46.94 \%$ \\
Link & $34.05 \%$ & $27.44 \%$ & $20.41 \%$ \\
Video & $15.17 \%$ & $46.93 \%$ & $24.49 \%$ \\
Status & 0 & $0.36 \%$ & $8.16 \%$ \\
\hline \multirow{2}{*}{ Total } & $\mathbf{1 0 0 \%}$ & $\mathbf{1 0 0 \%}$ & $\mathbf{1 0 0 \%}$ \\
\hline \multicolumn{2}{c}{ Source: Our elaboration. }
\end{tabular}

\section{Communication strategies}

Communication strategy adopted by the political parties during the electoral campaign was investigated by elaborating a variable named "Post Function". The variable is articulated on three general macro-categories, describing three main strategies: "Negative campaign", which contains adversary's attacks and denigration functions; "Political proposal", which illustrates the program points and the actions carried out by the political parties; and "Engagement", that aims to involve the voters proposing to be militant 2.0, who act in first person on the digital campaign of the political party.

The variable "Post Function" (Table 5.) confirms the hypothesys of the propensity to adopt a Negative campaign strategy: in fact, about $48.8 \%{ }^{2}$ of the published posts aim to persuade the voter by denigrating the political opponent and by using negative feelings. About $11 \%$ of posts use clearly Negative and Negative-Comparing modalities; $9.40 \%$ denounce circumstances of political relevance through the use of statistical data; $8.80 \%$ generate fear and concern about events reported; while $17.4 \%$ recall specific dramatic news events.

\footnotetext{
2 Cumulative percentage of Negative, Negative Comparing, Data declaration, Irony/parod/sarcasm, Fear and Current events modes.
} 
Table 5. Post Function

\begin{tabular}{lc}
\hline Post Function & \% \\
\hline Negative & 8.4 \\
Negative Comparing & 2.9 \\
Data Declaration & 9.4 \\
Irony/Parody/Sarcasm & 1.9 \\
Fear & 8.8 \\
Current Events & 17.4 \\
Past Political Achievements & 1 \\
Political Program & 12.3 \\
Political Issues & 3.1 \\
Identity Membership & 1.5 \\
Feeling good & 3.6 \\
Media Agenda & 5 \\
Territorial Agenda & 11.9 \\
Online Mobilization & 11.7 \\
Fundraising & 1 \\
\hline Total & $\mathbf{1 0 0}$ \\
\hline
\end{tabular}

Source: Our elaboration.

Considerated the minority of the other two communication strategies, our attention is focused on the analysis of the prevailing negative. The Lega is the party most oriented to the Negative campaign. It publishes posts that recall facts of crime or illegality (about 19\% of posts) that aim to emotionally shake the voters causing fear and worry (about $11 \%$ of posts). Even the Movimento 5 Stelle adopts the Negative strategy, by directly attacking the opposing political parties in a comparison of the political proposal (about 10\% of posts) and using statistical data to highlight what differentiates it from others (about 13\% of posts).

The Partito Democratico, the outgoing government party, is the only party that does not use negative strategies. It focuses its communication on the policy proposal aimed at explaining and illustrating the actions taken and the program points (about $37 \%$ of posts). 


\section{Conclusive observations}

As emerged in the course of the discussion, the online electoral campaign of the three parties has returned a composite and descriptive picture of their communicative peculiarities.

The overall sample of the materials, collected in the two weeks of monitoring, describes a consistent and unequivocal protagonism of the Lega, followed by the Partito Democratico, whose online campaign appears truthfully inconsistent, if compared to the other two political forces, and not perfectly in line with languages and tones of immediacy imposed by the online network. If the Lega and the Movimento 5 Stelle aim to hit the imagination of the electorate with images and videos of immediate use, the Partito Democratico produces long text posts that imply voluntary activation by the user. The negative tones, as supposed in the introduction, play a key role. For the Lega, news events are the basis for the elaboration of the negative political messages, that are based on verbal and symbolic violence, without any programmatic political proposal. The target of its negative propaganda is the left, the European Community and the immigration phenomenon meant as a threat to national security. The negative tones of the Lega are full of ideological political references that refer to xenophobia, nationalism and anti-Europeanism. The negative trend of the Movimento 5 Stelle is in line with its nature of post-ideological political movement and aims to build its image according to a denouncing and contrasting strategy towards the political adversaries. The Movimento 5 Stelle does not express any ideological value and does not take sides on the news events that have strongly influenced the debate in the electoral campaign. If the Lega and the Movimento 5 Stelle propose an electoral campaign of attack; the Partito Democratico plays an electoral campaign in a defense tactics, but, considering the effective electoral results and the poor digital campaign, it did not exert much appeal on voters.

\section{References}

Castells, M. (2009). Comunicazione e potere. Milano: Università Bocconi Editore.

Chadwick, A. (2013). The Hybrid Media System: Politics and Power. New York: Oxford University Press.

Diamanti, I., Lazar, M. (2018). Popolocrazia. Bari - Roma: Laterza.

Fukuyama, F. (1992). La fine della storia e l'ultimo uomo. Milano: Rizzoli.

Holtz-Bacha, C. (2016). Europawalkampf 2014. Berlin: Springer Vs.

Manin, B. (2016). Principi del governo rappresentativo. Bologna: Il Mulino.

Norris, P. (2000). A Virtuous Circle. Political Communications in Postindustrial Societies. Cambridge: Cambridge University Press.

Raine, L., Wellman, B. (2012). Networked. Cambridge: Mit Press. 